\title{
Giant tortuous umbilical vein in a cirrhotic patient
}

\section{Yao Xiao, Shunda Du}

Department of Liver Surgery, Peking Union Medical College Hospital, Beijing, China

Correspondence to: Professor Shunda Du. Department of Liver Surgery, Peking Union Medical College Hospital, No. 1 Shuaifuyuan Wangfujing, Beijing 100730, China. Email: dushd@pumch.cn.

Submitted Aug 03, 2020. Accepted for publication Aug 13, 2020.

doi: 10.21037/hbsn-20-636

View this article at: http://dx.doi.org/10.21037/hbsn-20-636
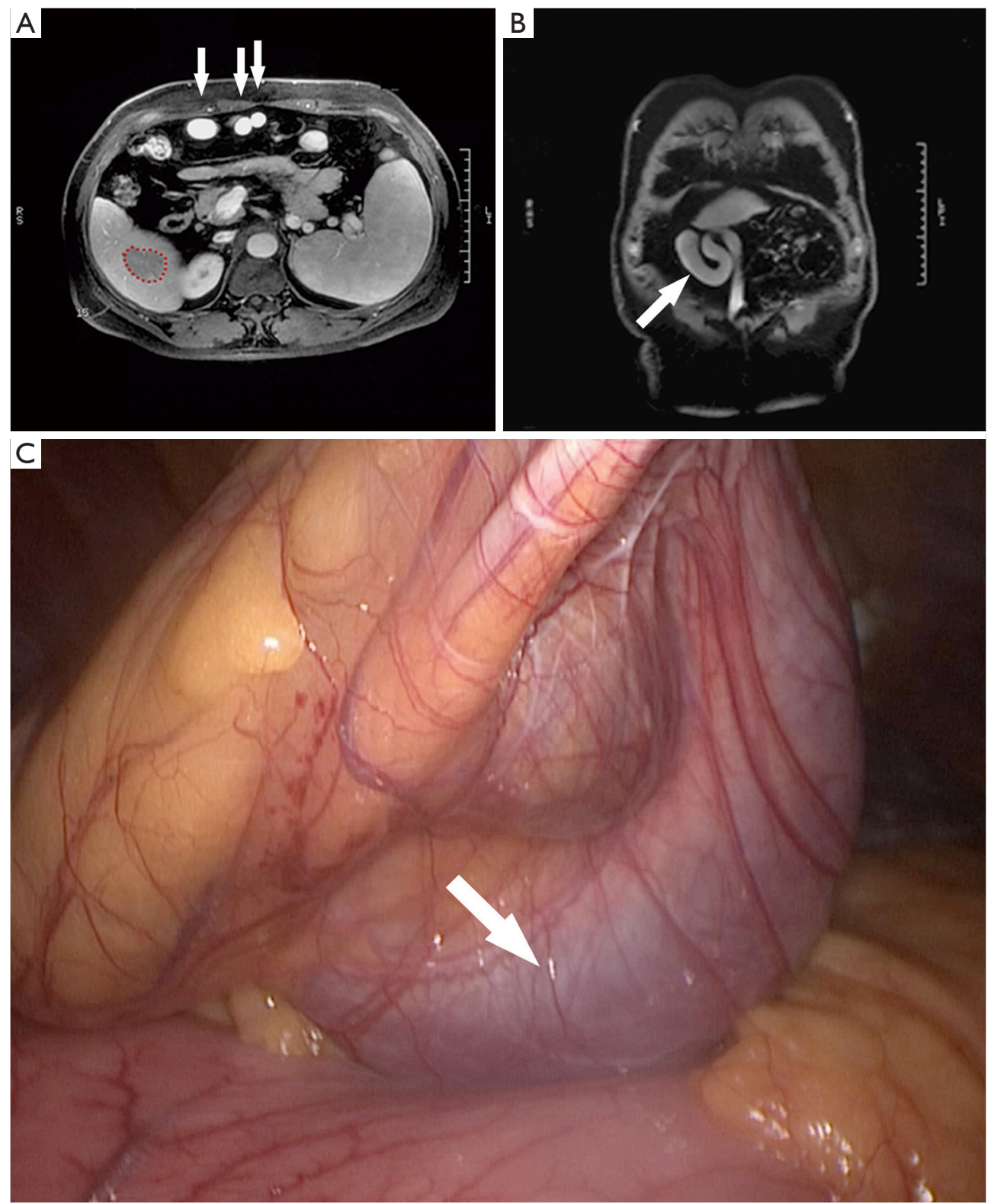
A 59-year-old male was admitted to our department with abdominal distension, splenomegaly and liver cirrhosis. MRI showed a Segment-6 tumor (Panel A) and a giant dilated vein (Panel A and B). During the laparoscopic hepatectomy, a tortuous umbilical vein was found (Panel C). The patient had no complications or recurrence in an 8-month followup. Patent umbilical vein exists in about $7.4 \%$ cases of liver cirrhosis, more than $50 \%$ of which are accompanied by other collateral shunts such as esophageal, perisplenic or mesenteric veins. It was very unusual that the patient had liver cirrhosis and a giant umbilical vein but no other collateral shunts. We speculate this giant umbilical vein with the diameter of $28.0 \mathrm{~mm}$ (3.5 times of the mean value of $7.97 \mathrm{~mm}$ ) may exert sufficient function to reduce the hepatic inflow pressure to a degree that other portal vein branches can be protected from dilation.

\section{Acknowledgments}

The authors thank to Dr. Gang Xu and Dr. Xueshuai Wan for providing technical help to this research.

Funding: This study was funded by CAMS Innovation Fund for Medical Sciences (CIFMS) (No. 2016-I2M-1-001) and the National Natural Science Foundation of China (Grant No. 81972698).

\section{Footnote}

Provenance and Peer Review: This article was a standard submission to the Hepatobiliary Surgery and Nutrition. The article did not undergo external peer review.

Conflicts of Interest: Both authors have completed the ICMJE uniform disclosure form (available at https://hbsn.amegroups. com/article/view/10.21037/hbsn-20-636/coif). The authors have no conflicts of interest to declare.

Ethical Statement: The authors are accountable for all aspects of the work in ensuring that questions related to the accuracy or integrity of any part of the work are appropriately investigated and resolved. Written informed consent was obtained from the patient for publication of this manuscript and any accompanying images.

Open Access Statement: This is an Open Access article distributed in accordance with the Creative Commons AttributionNonCommercial-NoDerivs 4.0 International License (CC BY-NC-ND 4.0), which permits the non-commercial replication and distribution of the article with the strict proviso that no changes or edits are made and the original work is properly cited (including links to both the formal publication through the relevant DOI and the license). See: https://creativecommons.org/ licenses/by-nc-nd/4.0/.

Cite this article as: Xiao Y, Du S. Giant tortuous umbilical vein in a cirrhotic patient. HepatoBiliary Surg Nutr 2021;10(3):428-429. doi: 10.21037/hbsn-20-636 